\title{
The Municipality's Role in a Smart Internet of Things Ecosystem
}

\author{
Per J. Nesse, Norwegian University of Science and Technology, Norway \\ Ida C. Lindtvedt, Norwegian University of Science and Technology, Norway \\ Ragnhild S. Frøhaug, Norwegian University of Science and Technology, Norway
}

\begin{abstract}
This article explores how municipalities plan and utilize internet of things (IoT) for smart city development, as well as how they collaborate with actors in the IoT ecosystem. To do so, in-depth interviews and secondary information are collected from municipalities in Norway. Overall, the empirical findings confirm that IoT has the potential to make municipalities smarter by improving public services, efficiency of internal management, and service delivery. The findings from this study are novel and can help executives to gain practical insight into the theory-heavy subject of smart city development in small and medium-sized municipalities.
\end{abstract}

\section{KEYWORDS}

Ecosystem, Internet of Things, Norway, Small and Medium-Sized Municipalities, Smart Cities

\section{INTRODUCTION}

Public service organizations across the world are changing due to ever increasing factors of urbanization, demography and population age (European Commission, 2019). Municipalities are challenged by increasingly complex tasks and service volume that put pressure on public resources, requiring them to innovate their services and implement new technology solutions to perform tasks more efficiently. To better handle this situation, the concept of smart city development has gained ground

The general aim of smart city development is to provide citizens with more efficient services by monitoring and optimizing existing infrastructure, increasing collaboration amongst actors and by encouraging innovative business models in both private and public sectors (Appio, Lima, \& Paroutis, 2019). In order to achieve this, smart cities rely on two things; 1) advanced technology to gather data and 2) human capital from collaboration with local and national actors. One of the main technologies assisting in the process of gathering data is the Internet of Things (Velsberg, 2019). One municipal department suitable for IoT and sensor monitoring is the technical sector. The main tasks within the technical sector include operation and maintenance of municipal roads, as well as water and wastewater. It also includes tasks in fire protection, construction case management and water - and air quality monitoring. Hence, the technical sector is a municipal department that could 
experience great potential cost reductions and higher quality of services through the introduction of IoT and sensors into the services (Statistics Norway, 2019).

Most of the research regarding smart city and public sector innovation predominantly focuses on larger cities, making it more challenging for smaller cities to know what findings are transferable to local communities. This study addresses the gap in the research regarding practical insight into IoT-enabled smart city initiatives in medium-sized municipalities. It performs a multiple case study analysis on four municipalities in Norway, and attempts to answer the following research questions: How does municipalities plan for and utilize IoT in smart city development and how do they collaborate with other actors in the IoT-ecosystem? The remainder of the article is organized in the following sections: literature review, research methodology, analysis and discussion (including an extended explanation of the research questions), and a conclusion.

\section{LITERATURE REVIEW}

This section presents the findings of the literature review related to using IoT in the public sector; it then elaborates upon the smart city concept. Finally, it presents the literature search findings regarding innovation ecosystems and forms of inter-municipal collaboration.

\section{IoT in the Public Sector}

The Internet of Things (IoT) refers to the inter-connection and exchange of data among devices/ sensors. It further includes the ability to aggregate, merge, analyse and process the collected data to obtain actionable information. Here the goal is to provide intelligent and complicated services in a multitude of areas, enabling the transparent and seamless integration of a variety of end systems (Mekki, Bajic, Chaxel, \& Meyer, 2019; Abualese, Al-Rousan, \& Al-Shargabi, 2019). Among others, IoT can be used to improve or create new public services, improve efficiency of internal management and service delivery, and drive collaboration with various actors (Velsberg, 2019).

IoT systems in municipalities may consist of interconnected devices and sensors distributed in houses, vehicles, streets, buildings and many other public environments to provide new services and the technical infrastructure needed to create public value through the use of data (Díaz-Díaz, Muñoz, \& Pérez-González, 2017). However, due to the dynamic nature of public services, the requirements for IoT devices vary significantly. For example, IoT devices that quickly and accurately transmit information can be crucial for winter road maintenance, while speed would not be a requirement for water quality monitoring (Velsberg, 2019).

In addition, IoT brings new possibilities for citizen involvement and participation that enhances public service delivery, increase trust in government, and strengthens community factors. It also facilitates data-sharing based on actors' personal affections, concerns, and solidarity to their neighbourhood (Guenduez, Mettler, \& Schedler, 2020).

\section{Smart City - A Fuzzy Concept}

The goal of smart city initiatives is to "provide more efficient services to citizens, to monitor and optimize existing infrastructure, to increase collaboration amongst different economic actors and to encourage innovative business models in both private and public sectors" (Appio, Lima, \& Paroutis, 2019:1). In order to achieve this, technology tools such as IoT, open data analytics, sensors and connected devices have been found to be powerful (Ghanbari, Laya, Alonso-Zarate, \& Markendahl, 2017).

The concept of smart city has been researched for many years yielding contrasting views and a multitude of dimensions and practical applications. Mora, Deakin, \& Reid (2019) describe these oppositions in smart city research of four main dichotomies: technology-led or holistic, top-down or bottom-up, double or triple/quadruple helix, mono-dimensional or integrated. The technology-led versus holistic perspective is useful for discussing whether smart city development is best driven by 
focusing on the available technology, or if decision-makers also must consider the human, social, cultural, economic, and environmental factors. What primarily separates these views is the degree to which the city focuses on citizen participation (Berntzen \& Johannessen, 2016) and community building.

\section{Innovation Ecosystems and Inter-Municipal Collaboration}

To better understand collaboration structures for this innovation, the literature review drew on work by, among others Design and Architecture Norway (DOGA) (2019) and Russel and Smorodinskaya (2018). These publications reported that collaboration is a complex network form of interaction among businesses and other institutional actors. Such innovation ecosystems when cooperating actors have achieved a certain level of integration concerned with a joint identity, joint strategy and joint goals. The development of innovation ecosystems usually rests on formal and informal communication platforms tailored to enhancing open dialogue and collaborative activities. The collaborating actors aim to co-evolve capabilities by working both cooperatively and competitively to create better products and services (Russell \& Smorodinskaya, 2018).

Most research regarding collaboration and innovation ecosystem theory surrounds the business sector. The role of public actors in terms of collaboration is primarily only assessed in triple-helix research. There are few publications assessing forms of collaboration among actors within the public sector or inter-municipal collaboration. However, there are some Scandinavian studies that have explored inter-municipal forms of collaboration and the associated benefits (Helin, 2017; JuellSkielse, Lönn, \& Päivärinta, 2017). These studies have found that the development of inter-municipal collaboration rests on both formal and informal voluntary collaboration structures and communication platforms. Further, the aim is to co-evolve capabilities by working both cooperatively and competitively with other proximal municipalities to create better public services.

\section{The Norwegian Smart City Model}

Several factors make Norway an interesting country for studying smart city development in mediumsized municipalities. Design and Architecture Norway (DOGA) (2019) cites to values of transparency, inclusion and equality as the building blocks of the Norwegian society and hence the Norwegian Smart City model. Furthermore, local autonomy in the public sector is high, there are long traditions for collaboration across sectors, the country's digital infrastructure is highly developed, and digital competence among the population is high (DOGA, 2019; KMD, 2020). In addition, the government ensures the interests of both urban and rural areas to secure optimal utilisation of resources throughout the country. Because of these factors, Norway has the necessary building blocks and platform to develop smart and sustainable solutions and services that can be scaled and exported, which in turn contributes to growth and value creation (DOGA, 2019).

Norway has a well-developed fourth generation (4G) mobile network, covering almost every rural area and hectare of the elongated country. The country is continuously improving communication infrastructure. Thus, a priority area in the Norwegian Government plan is to deploy a nationwide $5 \mathrm{G}$ network by 2023 (KMD, 2020). The aim of this is to leverage the opportunities provided by $5 \mathrm{G}$ networks and technology, such as IoT. IoT solutions in Norway are run on the 4G networks, but because $5 \mathrm{G}$ has higher speed and capacity and can detect weaker signals, the new network will play a significant part in the development of IoT. Increased capacity on the network is particularly important in densely populated areas (KMD, 2020).

The term IoT is juxtaposed to the use of sensors, an ever-increasing number of sensors are connected to the Internet. Sensors are used in everything from mobile phones and smart home solutions to devices measuring air pollution, water quality, noise levels. The sensors continuously collect data that, if properly handled, can be used in predictive maintenance, decision processes and development of new business models (The Explorer, 2019). 
The Norwegian government strongly believes in opening up data and they run a national registry of open data from the public sector (KMD, 2019). Access to open data sources makes it easier for entrepreneurs, innovators and other stakeholders to identify problems and opportunities, as well as develop smart solutions to smarter municipalities.

\section{RESEARCH METHODOLOGY}

A multiple case study analysis was chosen to study how medium-sized municipalities plan for and utilize IoT in smart city development. As Mora, Deakin, \& Reid (2019) pointed out, the ambiguity surrounding smart city research demonstrates that more empirical knowledge needed to understand the practical and technological implication of smart city development. One strength of a case study methodology is that it enables researchers to deal with the full range of gathered evidence such as documents and interviews. Each of the steps are described in the following sub-sections.

\section{Case Selection}

This article focuses on IoT and smart city development in medium-sized municipalities because Norway consists of mostly small and medium-sized municipalities. The case-municipalities has between 20.000 and 60.000 inhabitants. The size interval was set to include case municipalities large enough to initiate their own IoT projects, but small enough that they differ from larger cities with respect to demographic, social and economic characteristics. Additionally, most smart city research focuses on larger cities, leaving room for more research on medium-sized and small municipalities. Further, a unifying criteria (Stake, 2013), of the selected case-municipalities is that they have initiated at least one smart city-project in technical sector enabled by IoT. In addition, all four municipalities has plans to further expand their smart city development efforts. Next, the chosen cases are at the forefront of smart city development among medium-sized Norwegian municipalities.

To select medium-sized municipalities meeting the size and smart city criteria, the authors attended a municipal conference and spoke to experts on the IoT market. First, the authors attended an online seminar arranged by Telenor on the topic of smart municipality and IoT. During this seminar, several Norwegian municipalities presented their current efforts within smart city development. In addition, the authors spoke with experts on IoT and its presence in Norwegian municipalities. Next, the authors selected four municipalities among those mentioned at the conference or by the expert to serve as the case municipalities based on the aforementioned criteria.

\section{Data Collection}

Information about the four municipalities were initially collected through websites, reports and articles available online. Thus, the authors had knowledge about several areas of the smart city development in the selected cases before the interviews were held. Next, the authors conducted a one-hour semistructured interview with a smart city manager in each of the municipalities in the period of March to April 2020. For two of the case municipalities, the interviews supplement previous interviews, conducted in 2019 by the connectivity company Telenor. Also, all the municipalities received an e-mail with follow up questions to be answered by the interview subject in order to supplement the analysis. Three out of four digitalization managers responded to this email. Table 1 gives an overview of the type of data collected, as well as the related informants and authors.

In addition to the semi-structured interviews, secondary data about national influences were collected that included national digitalization strategies and different reports on the state of smart city development and digitalization in Norway. A detailed description of each case municipality can be found below, here referred to as M1, M2, M3 and M4:

M1: The municipality has approximately 30.000 inhabitants and is a significant industrial and agricultural municipality as well as an important regional center for neighbouring municipalities. It has two institutions of higher education within technology and smart city programs, but it has not 
Table 1. Overview of data

\begin{tabular}{|l|l|l|}
\hline \multicolumn{1}{|c|}{ Data format } & \multicolumn{1}{|c|}{ Description } & \multicolumn{1}{c|}{ Sources } \\
\hline Interviews & $\begin{array}{l}\text { Four interviews with four informants from four different } \\
\text { municipalities }\end{array}$ & $\begin{array}{l}\text { Digitalization and smart city } \\
\text { leaders }\end{array}$ \\
\hline Documents & $\begin{array}{l}\text { Municipal strategies and documents regarding smart city } \\
\text { national digitalization and smart city reports and strategies }\end{array}$ & $\begin{array}{l}\text { National government, DOGA, } \\
\text { Rambøll Mangement Consulting }\end{array}$ \\
\hline Statistical data & Municipal statistics & Statistics Norway \\
\hline Online resources & $\begin{array}{l}\text { The municipalities own web pages, project documents, } \\
\text { strategies and reports }\end{array}$ & The municipalities \\
\hline
\end{tabular}

an IoT-strategy for smart city development. M1 has developed and tested smart city solutions within buildings, infrastructure, mobility/transport, welfare technology and learning/education.

M2: The municipality has approximately 60.000 inhabitants and is categorized as a somewhat urbanized region. It does not have a university or higher education education, but it views academia as an important actor in its collaborating with the local high schools to create technology interest. M2 has a smart city strategy, but not an IoT-strategy for smart city development. M2 is utilizing IoT and has developed an e-government mobile app for citizen participation and information-sharing

M3: The municipality has approximately 50.000 inhabitants and is the largest municipality in its rural region. It is a significant center of trade, education and communication centre for small and medium sized enterprises operating within metal, machinery and food industries. It does not have an IoT-strategy, but it does have a smart city strategy. M3's website refers to different initiatives/projects within welfare technology in elderly, including driver-less vehicles in the city center.

M4: The municipality has approximately 30.000 inhabitants and is categorized as an urbanized region hosting engineering, wood processing and pharmaceutical industry players. It has not developed an IoT-strategy, but it has a smart city strategy and smart program projects to stimulate experimentation, testing and demonstration of new technology, new services for citizens and new types of business models to create value for a more forward-looking society

\section{Data Analysis}

The present authors used a smart city framework adapted for IoT analysis. The framework is closely connected to that of Mora, Deakin, \& Reid (2019), but has been adapted to an IoT-perspective. The analysis is done in two steps: The first step identifies how the municipalities plan for and utilize IoT for smart city development, and the second step maps how the municipalities collaborate with actors in the IoT-ecosystem. These steps make it possible to map the municipalities' strategic focuses on IoT enabled smart city development. An overview of the analytical framework can be found in Table 2 .

The first analytical step codes the empirical findings into four dimensions; community building, strategies and workgroups, digital infrastructure, and service and application projects in technical municipal departments. These four dimensions correspond to the four dimensions in the smart city framework of Mora, Deakin, \& Reid (2019) identifying the strategic principles driving smart city development. The first dimension regards community-building activities to support the implementation of IoT projects. This entails activities stimulating citizen engagement and digital competence, user-driven innovation, community-led urban development, and activities informing the city's stakeholders. The second dimension, strategies and workgroups, identifies the activities aiming to guide and develop smart city development (e.g. action plans and road maps, assessment methods and workgroups). The third dimension maps the municipality's IoT-projects in technical departments. Finally, the fourth dimension maps activities aiming to develop the necessary digital infrastructure for IoT. The interview coding includes several steps; (1) identifying the activities each municipality undertakes that are related to how the municipality plans to utilize IoT in smart city 
Table 2. Analytical framework for loT-enabled smart city development.

\begin{tabular}{|c|c|}
\hline Analytical framework steps & Dimensions \\
\hline $\begin{array}{l}\text { Step 1: } \\
\text { Identifying important activities undertaken by the } \\
\text { case-municipalities }\end{array}$ & $\begin{array}{l}\text { - Community building } \\
\text { - Strategies and workgroups } \\
\text { - Digital infrastructure } \\
\text { - Services and Application projects in technical } \\
\text { municipality departments }\end{array}$ \\
\hline $\begin{array}{l}\text { Step 2: } \\
\text { Identifying important actors in the IoT-ecosystem }\end{array}$ & $\begin{array}{l}\text { - Private firms } \\
\text { - Academia } \\
\text { - Regional public actors } \\
\text { - Citizens } \\
\text { - Other municipalities } \\
\text { - Civil organizations }\end{array}$ \\
\hline
\end{tabular}

development, (2) categorizing the identified activities into one of the four dimensions of step 1, (3) identifying sub-groups within each dimension.

The second step identifies the actors in the ecosystem and their roles. This section analyses the findings with respect how the municipalities collaborate with actors in the IoT-ecosystem. As in step 1, the process of coding the interviews is done in three phases; (1) identifying the actors which contribute to smart city development in the municipality, (2) assigning a type to each contributing actor (private firm, academia, etc.) and (3) identifying the characteristics of the relationship between the municipality and each collaborating actor. In order to ensure that all information from the interviews is coded correctly, each interview is scrutinized several times. After the first categorization of the data, the authors also discuss and review the coding of the dimensions and the sub-groups several times.

\section{ANALYSIS}

\section{Step 1: Identifying Important Activities}

Step one, identifying important activities, first considers community building. This is defined as activities supporting the construction of an open and inclusive collaborative environment that is able to support the implementation of IoT projects. In the interviews, the smart city leaders of all the municipalities report that they focus on increasing citizen engagement and digital competence among citizens. For example, M2, M3 and M4 have established physical areas (e.g. smart streets, city labs and a smart bench) to showcase smart city technology (sensors, connected devices and IoT) and create engagement with IoT. In addition, all the municipalities focus on user-driven innovation and community-led urban development in order to fit IoT-projects to citizens' needs. Lastly, M3 stand out by performing activities that aim to improve information flow to the local businesses for increased local growth and community building.

Next, activities that strategically guide smart city development and provide plans and evaluation methods were identified. None of the case-municipalities have strategies or workgroups exclusively for IoT, but works towards smart city development in a coherent manner. In terms of action plans and goals providing strategic direction to IoT-enabled smart city development, all the municipalities has similar results regarding smart city goals. All four municipalities aim to select projects that provide citizens with better quality municipal services at a lower cost and more jobs for inhabitants through new business opportunities. Secondly, the municipalities also show similarities in how they evaluate IoT projects. All municipalities report that they use the national project management tool for innovation and digital projects. M1 stands out, stating that is uses the evaluation tool daily and strive to evaluate projects in a structured manner. Lastly, all the municipalities has some sort of workgroup 
Table 3. Type of loT-projects in technical sector.

\begin{tabular}{|c|c|c|c|c|}
\hline Application area & M1 & M2 & M3 & M4 \\
\hline Air quality & Pilot x 2 & No project & Pilot & Pilot \\
\hline Water temperature & No project & Pilot & No project & No project \\
\hline $\begin{array}{l}\text { Water/wastewater } \\
\text { management }\end{array}$ & Pilot & Planned & Pilot & Pilot \\
\hline Waste management & No project & No project & No project & Operations \\
\hline Streetlights & No project & Planned & No project & No project \\
\hline Mobility/transport & No project & Planned & Pilot (LS) & Operations \\
\hline $\begin{array}{l}\text { Winter road } \\
\text { maintenance }\end{array}$ & Pilot (LS) & Planned & No project & $\begin{array}{l}\text { Pilot/ } \\
\text { Operations }\end{array}$ \\
\hline Buildings management & Operations & No project & No project & Operations \\
\hline Fire safety & No project & No project & Pilot (LS) & No project \\
\hline $\begin{array}{l}\text { Web/mobile citizen } \\
\text { applications }\end{array}$ & No project & Operations & No project & Planned \\
\hline
\end{tabular}

Note: Planned: areas where pilot projects or large-scale pilots are planned/started. Pilot: small-scale innovative project with few actors. Large-scale (LS) pilot: large-scale innovative project involving multiple actors and business cases. Operations: project is fully implemented and finalized.

assigned to manage the strategic course of smart city development. The municipalities structure these workgroups differently, but focus on close collaboration with sector departments.

Further, services and applications map the municipalities' ongoing and planned IoT projects in the technical sector. The municipalities has initiated several IoT-projects in the technical sector. Table 3 categorizes the identified IoT projects of each municipality. Implementation of IoT in the different application areas have reached different levels of maturity in the different case municipalities. Some projects are at a planning stage, while others are small-scale innovative pilots featuring a small number of actors, and yet others are large-scale pilots that involve multiple actors and business cases. Last, some of the municipalities has IoT projects within the technical sector that are already operating, meaning that the project is fully implemented and finalized.

As seen in Table 3, most current IoT-projects are still in a piloting phase. The interviews gave some indications to why it is challenging to move a project toward operations. For example, M1 stated that scaling projects from the pilot phase has several challenges. The workgroup leading a successful pilot is often a small group of motivated people, but the sector that is going to use the solution in full scale usually needs much more motivation and training. Immature technology is also mentioned as a challenge to project scaling.

The municipality find that IoT technology and the IoT ecosystem is still immature. M2 report that there are many entrepreneurs and smaller companies that make sensors, but that few have managed to scale their production. Therefore, it is also a challenge to find sensors of sufficient quality to a specific application area. M1 has had a similar experience - a private company providing it with an IoT-solution has difficulties locating a suitable sensor supplier. Furthermore, when sensors were to be installed, the supplier failed to complete the task and had to involve an external actor for installation. M1 also found that the market is not able to provide the type of sensor that it needs for its services.

In terms of digital infrastructure, all of the municipalities use a LoRa- or NB-IoT network (LoRA alliance, 2019; GSMA, 2019) to collect sensor data. M1 and M2 use a LoRa-network provided by external partners. M2 preferred a LoRa-network because its implementation had proved successful in another municipality of larger size; here, M2 did not consider other LPWAN-technologies to be an option. In contrast, M1 an NB-IoT network for a project in its pilot phase. M3 makes a point out of being independent of technology networks and is open to using both LoRa and NB-IoT in order 
Table 4. Overview of actors and their contribution in the municipalities' loT-ecosystems

\begin{tabular}{|c|c|c|c|c|}
\hline Actor & M1 & M2 & M3 & M4 \\
\hline Private actor & $\begin{array}{l}\text { Local company: } \\
\text { Network } \\
\text { National company: } \\
\text { Platform } \\
\text { National company: } \\
\text { Network }\end{array}$ & $\begin{array}{l}\text { National } \\
\text { company: } \\
\text { Platform } \\
\text { National } \\
\text { company: Partner } \\
\text { network }\end{array}$ & $\begin{array}{l}\text { Local company: Tech \& } \\
\text { Automation } \\
\text { Local company: Network } \\
\text { National company: } \\
\text { Platform, network }\end{array}$ & $\begin{array}{l}\text { Local company: } \\
\text { Technology } \\
\text { National company: } \\
\text { Platform, Network }\end{array}$ \\
\hline Academy & $\begin{array}{l}\text { University: Research } \\
\text { University: Student } \\
\text { project }\end{array}$ & High school & $\begin{array}{l}\text { University: } \\
\text { Research } \\
\text { University: } \\
\text { Student project }\end{array}$ & $\begin{array}{l}\text { University: Research } \\
\text { University: Student } \\
\text { project }\end{array}$ \\
\hline Citizens & $\begin{array}{l}\text { Direct: Survey } \\
\text { Direct: Workshop }\end{array}$ & $\begin{array}{l}\text { Direct: Survey } \\
\text { Direct: User panel }\end{array}$ & Direct - City lab & $\begin{array}{l}\text { Direct: Survey, Social } \\
\text { media, City lab }\end{array}$ \\
\hline $\begin{array}{l}\text { Public } \\
\text { actors }\end{array}$ & Municipality & $\begin{array}{l}\text { Municipality } \\
\text { Local public } \\
\text { company }\end{array}$ & $\begin{array}{l}\text { Municipality } \\
\text { Regional public company }\end{array}$ & Municipality \\
\hline
\end{tabular}

Note: National private actor: large companies spanning across Norway that offer the municipality with comprehensive solutions, such as platform or connectivity companies. Local private company: a small and specialized private company stationed within the municipality.

to acquire the right technology. M4 only uses the NB-IoT network to push sensor data, but it has experienced challenges with mobile network deployment related to geographical factors.

\section{Step 2: Identifying the Actors in the loT-Ecosystem}

The second step of the analysis identifies the different actors, their role in the IoT ecosystem, and how they collaborate with the municipalities. The municipalities collaborate with many actors, both public and private, yet all the municipalities mention that the IoT-ecosystem of actors is complex and difficult to manage. Table 4 outlines the identified types of actors and their contribution on IoTprojects in the technical sector. The list is based on the interviews and is not necessarily complete.

As shown in Table 4, all municipalities collaborate with private actors, both local and national companies. The role of the private actors is first and foremost to provide technology solutions and new services. Sometimes the private actors are also used as pure process consultants, to map needs, and for method and service design.

In addition, the results reveal that the network of actors working with IoT is vast and complex. It is difficult to find companies delivering full IoT systems; furthermore, the private actors collaborated with the municipalities can be characterized as small and operate in niche markets. The municipalities report several challenges when collaborating with private companies, including immature technology which makes customization difficult, the companies being in an exploration phase themselves, using the municipalities as test rabbits and the companies having a preference for certain technologies.

All the case-municipalities collaborate with academic actors to some extent. The academic actors have a clear desire to get research funded and to access exciting topics for further research. M1, M3 and M4 are in unique positions, as they are situated in close proximity to universities offering them insights via research and IoT-development projects. The municipalities wish to provide the academic actors with assignments, seeing this as an activity that, in the long term, provides the municipalities with highly digitally competent academic institutions. Nevertheless, a challenge for the municipalities regarding research is its exploratory nature. Research processes might take years, while the municipalities request IoT-projects to show results that meet their needs in shorter time frames.

Further, M1, M2, and M3 see the importance of collaborating with academic institutions to increase competence in the local community through facilitating relevant projects for students. M2 also sees engaging younger people in IoT projects as important. The municipality is not situated 
close to a university, but it invites high school students to participate in smart city development and IoT projects to motivate and engage at a young stage. As mentioned in step 1 of the analysis, all the municipalities work towards citizen engagement in their IoT projects.

While collaborating with the above-mentioned actors fits the quadruple-helix model of innovation (Hasche, Höglund, \& Linton, 2019), the findings suggest another important form of collaboration for the case municipalities; inter-municipal collaboration. This form of collaboration was present in every case municipality; it provides advantages in terms of exchanging experiences. This is crucial, due to the complexity of the IoT ecosystem and difficulties when it comes to identifying credible suppliers. Hence, through inter-municipal collaboration, municipalities can share experiences with each other to ensure quality of collaboration with other actors in the IoT ecosystem (Markendahl, J.; Deij, L.T., 2018). M1 stated that the importance of inter-municipal collaboration could also be regional if all the municipalities in the same county joined forces in projects spanning across them to gain more power towards regional government structure.

The analysis shows that the smart city focus among the case municipalities is similar. First, the empirical findings indicate that all the municipalities has a holistic smart city strategies. The municipalities are influenced and driven by both technological advancements and multiple softer sides of smart city development, such as human, social and economic factors (Appio, Lima, \& Paroutis, 2019).

\section{DISCUSSION}

The research questions of this article asks how municipalities plan for and utilize IoT in smart city development and how the municipalities collaborate with actors in the IoT-ecosystem. This section discusses the question in more depth by relating the study's empirical findings to the previous literature.

\section{Managing loT Smartness}

All case-municipalities have a management team and a strategy guiding their smart city development. Most of the municipalities mentioned IoT implementation as a strategic choice. In addition, the interviewees appreciated that IoT quickly allows them to gain insight into valuable information that previously required a lot of resources. For example, the municipalities are now able to place sensors in public spaces to measure water temperature, air quality, and the efficiency of waste management. They have found that simple sensor measurements have made it possible to make simple estimates about potential savings, which has made decision-making and resource allocation easier. The benefit of quick IoT testing is also valued for the practices it encourages: "the great advantage of this data type is that it represents real-time information, generating minimal costs. It provides a new basis for government and administrative decisions: simple, needs-based, and cost-effective regulation and control can be achieved" (Guenduez, Mettler, \& Schedler, 2020:194).

Further, the literature is not clear regarding whether or not public sector organizations should have a specific IoT strategy for smart city development (Velsberg, 2019). However, some cities and municipalities adapt their practices more to the new technology, whereas others focus more on the technology being a substitute to already working practices (Guenduez, Mettler, \& Schedler, 2020). Mora, Deakin, \&Reid (2019) believe that the different technologies are less relevant than the service itself. This fits with the findings from the four case-municipalities, none of them have a specific IoT strategy. They wish to be technology-independent and able chose the technology that best fit each project at different times. M3 stated that their municipality only needs an IoT strategy when their sensors provide them with added value beyond the primary needs of the initial sensor placement. However, some researcher stress the importance of having a plan for IoT-implementation, explaining that municipal organization have to be aware of the needs of the technological components (Guenduez, Mettler, \& Schedler, 2020) and how the technology shapes the local environment and 
collaboration (Velsberg, 2019). Hence, as the findings suggest, public sector organizations and the case-municipalities can benefit from having a strategic plan for IoT implementation and management.

IoT-enabled smart city initiatives place high demands on public decision-makers as they must possess the technical, organizational, and managerial skills necessary to understand and control the new technologies (and because they are responsible for successful implementation and to secure added value to citizens) (KMD, 2020). These challenges becomes especially apparent in the procurement phase. With IoT, the municipality often has to use the national method for innovative procurement procedures. This involves making the public tender more general and with fewer specified requirements - here, the private actors must propose the best solutions, and the municipality must choose among the propositions (KMD, 2019b). However, technological procurement's regarding IoT is more complex because the sensor alternatives greatly varies in terms of technological requirements regarding range, network, open data and IoT platform (KMD, 2019b). Thus, one challenge with IoT-enabled smart city initiatives is the strain they put on municipal resources.

In terms of digital infrastructure, two out of the four municipalities has chosen a LoRaWan network and have left development and maintenance of the sensor network to external partners. M1 uses a private partner to maintain the LoRa-network, while M2 uses a public company. This is because the municipalities has no capacity to handle the network on a daily basis. For example, M2 stated that they much rather outsource the network management so that its IT department is able to handle their day-to-day work. For M2, type of network chosen by other municipalities inspired its own choice of network. In regard to relying on external system providers, Wirtz, Weyerer, \& Scchichtel (2019:343) find that public sector organization have to be cautious of the implications for their strategic decisions with regard to IT and data security: "governments and public organizations need to be strategically flexible in terms of providing an adaptive infrastructure that is able to cope with ever-changing security threats in the heterogeneous and dynamic IoT context". With this, the authors mean that public decision-makers have to understand the importance of strategy as an influential building block in the context of the IoT; further, they have to be able to challenge their strategy on a regular basis to adjust it over time.

\section{Collaboration with Private Actors and Academia and Citizens}

Wirtz, Weyerer, and Schichtel (2019) have identified that private companies and their respective networks play a significant role in IoT-projects. Outsourcing and collaboration with private actors is becoming increasingly important for public sector organizations (Falch \& Maestrini, 2019). The case municipalities also see collaboration with private actors as important; it is a big focus area in the digital strategy of Norway's public sector (KMD, 2019b). Further, when private and public actors collaborate on IoT projects, the actors take on different roles (Cavallini, Soldi, Friedl, \& Volpe, 2016). Usually the municipality handles regulation, while the implementation most often is performed by the private partner. Funding, however, can be private as well as public, and the public partner can also be involved in the design, monitoring, and management of a project (Falch \& Maestrini, 2019). The goal of the public actor for establishing such relationships is to partially transfer the risk involved in service provision from the public to the private sector and make use of private sector capabilities, such as capital or skills, in order to expand or increase efficiency in public services (Wirtz, Weyerer, $\&$ Schichtel, 2019). In the case municipalities, the empirical findings suggest that the aim of publicprivate partnerships is predominantly driven by the need for technological competence. Further, in terms of facilitation for local industrial growth, municipalities can improve and encourage growth in their local communities through collaboration with private actors (Falch \& Maestrini, 2019). The empirical findings in this regard, indicate that the case-municipalities in fact collaborate with local private actors to stimulate economic growth and development in the local community.

Next, the authors found that the case municipalities collaborate with a wide range of private actors on IoT projects, including large enterprises, smaller local companies and start-ups. They report that they often have to find the private partners through networking in their local community or at national 
conferences, or that they confer with other municipalities to find private partners for their IoT projects. They see this process as complex and time-consuming, and three out of four case municipalities wish for better overview of potential ecosystem actors. This correspond to previous findings that Norwegian municipalities in general find the ecosystem of private actors to be complex and difficult to navigate (Rambøll Management Consulting AS, 2019). However, the number of involved and unique actors in the IoT ecosystems in each case municipality suggests that they have a certain overview, and that they make an effort into involving more actors. One could argue that the case municipalities display culture of local inclusion and creative encouragement (in terms of including the local private actors) have a willingness to explore potential new service areas.

Velsberg (2019) have studied private-public goal-alignment and observed that IoT-smartness is best achieved when actor goals align or complement each other. The authors further state that when this happens, technology can be used to both enhance and transform organizational practices and processes, and the organizational culture can further support change. Tnhe interview with M2 revealed that the municipality ensured its vision and goals aligned with those of its private partner before officially initiating projects. M3 states that their long-term goal with smart city projects often is to create a service offer that can be transferred to other municipalities. This is a focus for two reasons; 1) M3 want their project to help reduce the number of duplicate IoT solutions, and 2) it wants its solution to be scalable in order to generate more interest both commercially and in private sector. M3 further expresses its wish for private actors to be the technical expert and for it to be a municipal expert providing crucial insight into creating the perfect service to fit its goals. This focus on goal-alignment can also be found in the literature as an important success factor. One study of innovation partnerships among public and private sectors points out the importance of building tools that enable an interactive dialogue and to work jointly to secure sustainable growth when purposes align (Russell \& Smorodinskaya, 2018). This is all to ensure continuously aligning development strategies and implementation processes.

Hasche, Höglund, and Linton (2019) highlight that academia is an important actor in collaboration. An interesting finding from the present analysis is that all case municipalities collaborated with academia to some extent. M1, M3 and M4 are in unique positions because they are situated in close proximity to universities that aid them throughout research and development phases of their IoT projects. M2 is not close to a university, but it still utilizes high schools to motivate and engage citizens at a young stage. Despite this, all the case municipalities pointed out how collaboration with academia can be challenging because the municipal project often are under strict time constraints, and research organizations often take too long to provide them with the necessary insight for their projects.

Furthermore, the approach the case municipalities take qualifies as the bottom-up approach to innovation (Mora, Deakin, \& Reid, 2019). This is because they aim to include multiple local actors in their innovation efforts, which focus on market-oriented and efficient public services. Lee, Hancock, $\& \mathrm{Hu}$ (2014) have found that such municipalities often become facilitators and central coordinators of the partnerships and the IoT-ecosystem. This correspond with the present study's findings and the fact that these projects seem to be organized to include multiple actors.

Our study has highlighted the importance of the citizens role in IoT enabled smart city development (Giffinger, Kramar, Kalasek, Pichler-Milanovic, \& Meijers, 2007). In the case municipalities, citizens are invited to participate through workshops, panel testing, surveys and city labs. A challenge with this form of active collaboration is that citizens may be reluctant to join a focus group or join a town hall meeting due to time and space constraints (Berntzen \& Johannessen, 2016). However, Guenduez, Mettler, \& Schedler (2020) argue that sensors and connected devices will provide citizens with new and improved methods of active participation through open innovation and collaboration. The authors further post that IoT can create and improve the municipal environment so that involvement and participation enhances public service delivery and strengthen community factors. This can be done by showcasing application areas for IoT to citizens and encourage them to learn more about 
IoT use. However, in order to gain the full benefits of IoT in citizen collaboration, the municipality has to facilitate and encourage citizens to gather and share sensor data.

\section{Inter-Municipal Collaboration in Smart City Development}

Similar to other Scandinavian studies of inter-municipal collaboration (Juell-Skielse, Lönn, \& Päivärinta, 2017), the present study have identified that the development of inter-municipal collaboration rests on both formal and informal voluntary collaboration structures and communication platforms. Further, the aim of inter-municipal collaboration here is to co-evolve capabilities by working both cooperatively and competitively with other municipalities in proximity to create better public services. This article have also identified informal structures of inter-municipal collaboration corresponding to studies of Wiberg and Limani (2015) and Helin (2017). It is not certain why these voluntary forms of collaboration occur, but the municipalities' local autonomy and scarce resources might have an effect. Analysis of the empirical findings have identified "knowledge communities" with characteristics of informal collaboration through networking and exchanging experiences with other municipalities at conferences and digital forums. In addition, the analysis identified "transferring solutions" as a commonly applied form of inter-municipal collaboration. The municipalities stated that they aim to apply other municipality's smart solutions to their own local environment, and vice versa. A stated challenge from all of them is that a solution that works in one municipality often has to be adjusted or re-designed to work in other municipalities. However, the positive aspects of this latter form of informal collaboration is that it limits the number of duplicate solutions, which help simplify and improve the solution.

The formal inter-municipal collaboration structure that takes a project-based form has similarities with the formal collaboration identified by Helin (2017) and (Wiberg \& Limani, 2015). These collaborations range from two municipalities to more joint initiatives with additional municipalities in a regional county and/or in a cross-regional context (Wiberg \& Limani, 2015). The municipalities both invest resources into a smart city project, which results in a product or service to be used by all involved municipalities. Further, the size of the collaborating municipalities influences resource allocation and decision-making timelines. Despite these findings, it is important to note that more research is needed to gain a deeper understanding of the various forms of collaboration as well as benefits and challenges of inter-municipal collaboration in terms of smart city-projects utilizing IoT.

\section{CONCLUSION AND FURTHER RESEARCH}

The Norwegian medium sized municipalities studied in this article work strategically toward smart city development. The municipalities see IoT as a means to reach smart city objectives, but they do not see IoT as a goal in itself. The case municipalities aim to include both smaller and bigger businesses for increased technology competence and financial resources. The role of academia is to provide insight into technology development, and the municipalities see collaboration with this actor as a beneficial investment for increased ICT competence in the future. However, the IoT-ecosystem they use for collaboration is complex and difficult to navigate. Our contribution to the research on IoT enabled smart city research is that inter-municipal collaboration is important to navigate the IoT ecosystem.

There are some limitations of this study that should be mentioned. First, the results and reliability may have been influenced by single source bias, as the interviews were with only one municipal smart city representative. In order to control for this, the authors read municipal websites as well as reports and documents describing aspects of the IoT projects have been read to supplement the data from the interviews. Further research might focus on how the inter-relations among actors evolve over time by studying specific IoT projects in even more detail. Internal municipal processes and organizational roles are also areas of further research to gain insight in smart city development. 


\section{REFERENCES}

Abualese, H., Al-Rousan, T., \& Al-Shargabi, B. (2019). A new trust framework for e- government in cloud of things. International Journal of Electronics and Telecommunications, 65(3), 397-405.

Appio, F., Lima, M., \& Paroutis, S. (2019). Understanding smart cities: Innovation ecosystems, technological advancements, and societal challenges. Technological Forecasting and Social Change, 142, 1-14. doi:10.1016/j. techfore.2018.12.018

Berntzen, L., \& Johannessen, M. (2016). The Role of Citizen Participation in Municipal Smart City Projects: Lessons Learned from Norway. Springer International Publishing.

Cavallini, S., Soldi, R., Friedl, J., \& Volpe, M. (2016). Using the quadruple helix approach to accelerate the transfer of research and innovation results to regional growth. Consortium Progress Consulting Srl \& Fondazione FoRmit.

Díaz-Díaz, R., Muñoz, L., \& Pérez-González, D. (2017). Business model analysis of public services operating in the smart city ecosystem: The case of smartsantander. Future Generation Computer Systems, 76, 198-214. doi:10.1016/j.future.2017.01.032

DOGA. (2019). Roadmap for smart and sustainable cities and communities in Norway. Retrieved April 13, 2020, from Design and Architecture Norway (DOGA), the Norwegian Smart City Network, Nordic Edge: https:// doga.no/globalassets/pdf/smartby-veikart-19x23cm-eng-v1_delt.pdf

European Commision. (2019). The future of cities. Retrieved April 25, 2020, from https://ec.europa.eu/futurium/ en/system/files/ged/the-future-of-cities_online.pdf

Falch, M., \& Maestrini, M. (2019). Public private partnership in smart city waste management-a business case. In IEEE (Ed.), CTTE-FITCE: Smart Cities \& Information and Communication Technology (pp. 1-6). CTTEFITCE. doi:10.1109/CTTE-FITCE.2019.8894820

Ghanbari, A., Laya, A., Alonso-Zarate, J., \& Markendahl, J. (2017). Business development in the internet of things: A matter of vertical cooperation. IEEE Communications Magazine, 55(2), 135-141. doi:10.1109/ MCOM.2017.1600596CM

Giffinger, R., Kramar, C., Kalasek, R., Pichler-Milanovic, N., \& Meijers, E. (2007). City ranking of European medium sized cities. Retrieved from. http://smart-cities.eu/download/city_ranking_final. pdf

GSMA. (2019). Narrowband - Internet og Things (NB-IoT). Retrieved March 17, 2020, from https://www.gsma. com/iot/narrow-band-internet-of-things-nb-iot/

Guenduez, A., Mettler, T., \& Schedler, K. (2020). Citizen Participation in Smart Government: A Conceptual Model and Two IoT Case Studies. Springer International Publishing.

Hasche, N., Höglund, L., \& Linton, G. (2019). Quadruple helix as a network of relationships: Creating value

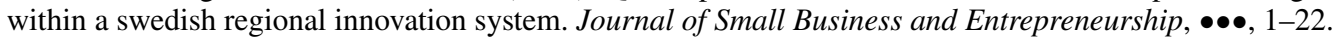

Helin, A. (2017). Secos as a mean to survive?-case municipal ict. Proceedings of 9'th International Confernece onSoftware Ecosystems (IWSECO2017), 114-126.

Juell-Skielse, G., Lönn, C.-M., \& Päivärinta, T. (2017). Modes of collaboration and expected benefits of interorganizational e-government initiatives: A multi-case study. Government Information Quarterly, 34(4), 578-590. doi:10.1016/j.giq.2017.10.008

KMD. (2019). One digital public sector - digital strategy for the public sector 2019-2025. Retrieved April 15, 2020, from Norwegian Ministry of Local Government and Modernization: https://www.regjeringen.no/en/ dokumenter/one-digital-public-sector/id2653874/?ch=1

KMD. (2019b). De nordiske landenes strategier for innovasjon i offentlig sektor [The Nordic countries' strategies for innovation in public sector]. Retrieved from Norwegian Ministry of Local Government and Modernisation: https://www.offentliginnovasjon.no/ files/2020/01/De-nordiske-landenes-innovasjonsstrat.pdf

KMD. (2020). National strategy for artificial intelligence. Retrieved from Norwegian Ministry of Local Government and Modernization: https://www.regjeringen.no/contentassets/ 1febbbb2c4fd4b7d92c67ddd353b6ae8/en-gb/pdfs/ ki-strategi_en.pdf 
Lee, J., Hancock, M., \& Hu, M.-H. (2014). Towards an effective framework for building smart cities: Lessions from Seoul and San Francisco. Technological Forecasting ans. Social Change, 89, 80-99.

LoRA alliance. (2019). Lorawan - creating valuable iot connections. Retrieved March 17, 2020, from https:// lora-alliance.org/sites/default/files/2019-03/LA_AnnualReport_External_2019_0.pdf

Markendahl, J., \& Deij, L. (2019). Nuläge, planer, och förutsettningarn för digitalisering av infrastrucktur $i$ mindre kommuner. Academic Press.

Markendahl, J., \& Deij, L. T. (2018). Effectiv ICT använding och utbyggnad av infrastruktur, samverknad inom och mellan kommuner (Efficient use and deployment of ICT infrastructure and collaboration within and between municipalities). Working Paper, KTH.

Markendahl, J., Lundberg, S. O. K., \& Movin, S. (2017). On the role and potential of IoT in different industries: Analysis of actor cooperation and challenges for introduction of new technology. In IEEE (Ed.), Internet of Things Business Models (pp. 1-8). Users, and Networks. doi:10.1109/CTTE.2017.8260988

Mekki, K., Bajic, E., Chaxel, F., \& Meyer, F. (2019). A comparative study of lpwan technologies for large-scale iot deployment. ICT Express, 5(1), 1-7.

Ministry of Local Government and Modernization (KMD). (2020). National strategy for artificial intelligence. KMD.

Mora, L., Deakin, M., \& Reid, A. (2019). Strategic principles for smart city development: A multiple case study analysis of european best practices. Technological Forecasting and Social Change, 142, 70-97. doi:10.1016/j. techfore.2018.07.035

Rambøll Management Consulting, A. S. (2019). IT I PRAKSIS 2019. Retrieved April 2, 2020, from https://www. ikt-norge. no/nyheter/it-i-praksis-2019-norges-digitale-tilstand-innbyggerne-vil-delel

Russell, M., \& Smorodinskaya, N. (2018). Leveraging complexity for ecosystemic innovation. Technological Forecasting and Social Change, 136, 114-131. doi:10.1016/j.techfore.2017.11.024

Spicer, Z., Goodman, N., \& Olmstead, N. (2019). The frontier of digital opportunity: Smart city implementation in small, rural and remote communities in Canada. Urban Studies (Edinburgh, Scotland), 1-24. doi: $10.1177 / 0042098019863666$

Stake, R. (2013). Multiple case study analysis. Guilford press.

Statistics Norway. (2019). Digitalisering i kommunene [Digitalization in municipalities]. Retrieved April 15, 2020, from https://www.ssb.no/teknologi-og-innovasjon/artikler-og-publikasjoner/digitalisering-i-kommunene

The Explorer. (2019). Smart cities in norway enhance quality of life and reduce emissions. Retrieved March 17, 2020, from https://www.theexplorer.no/stories/smart-cities2/ smart-cities-in-norway-enhance-quality-oflife-and-reduce-emissions/

Velsberg, O. (2019). The outcomes of the implementation of internet of things: A public value perspective. In Internet of Things. Information Processing in an Increasingly Connected World. IFIPIoT 2018. IFIP Advances in Informationand Communication Technology (vol. 548). Springer.

Wiberg, U., \& Limani, I. (2015). Intermunicipal collaboration: A smart alternative for small municipalities? Scandinavian Journal of Public Administration, 19(1), 63-82.

Wirtz, B., Weyerer, J., \& Schichtel, F. (2019). An integrative public iot framework for smart government. Government Information Quarterly, 36(2), 333-345. doi:10.1016/j.giq.2018.07.001 
Per J. Nesse is Associate Professor at NTNU, Industrial Economics and Technology Management department. Nesse is also Senior Research Scientist in Telenor Research. He is as specialist in service innovation management and corporate entrepreneurship and has extensive experience from managing $E U$ research and innovation projects together with international enterprises and universities. Nesse holds a Ph.D from Norwegian University of Science and Technology (NTNU) and a Master of Science in Business from Nord University in Norway. Nesse has published scientific articles in journals such as International Journal of Entrepreneurial Venturing, Journal of Information Technology and Management and European Journal of Operational Research.

Ida Cathrine Ringdal Lindtvedt holds a Master of Science from the Norwegian University of Technology Management. She is specialized in strategic business development and project management. In addition, she has a technological specialization within naval architecture to obtain unique knowledge in regards to technology, finance and management.

Ragnhild Skirdal Frøhaug holds a Master of Science from the Norwegian University of Science and Technology in Industrial Economics and Technology Management. She is specialized in strategy and international business development. In addition, she has a technological specialization within computer science and artificial intelligence. Through her degree, she has obtained knowledge in both technology, finance, and management. 